\title{
Developing Items Using by Pilot Test, Confirmatory Factor Analysis Statistical in Literacy for Communication and Supervision Clinical Elements Provider
}

\author{
Nor Shela Saleh \\ Faculty of Management, Universiti Teknologi Malaysia \\ shela_saleh87@yahoo.com.my \\ Hashim Fauzy Yaacob \\ Faculty of Management, Universiti Teknologi Malaysia \\ Mohd Shafie bin Rosli \\ Faculty of Education, Universiti Teknologi Malaysia
}

Doi:10.5901/mjss.2015.v6n2p202

\begin{abstract}
This research about the communication and supervision developments as an element in the future set of questionnaire. The set of questionnaire aspect need regarding medical learning of trainee doctor. The selected of two elements based on previous research, the theory and model support the importance of both. The researcher also use several of set a questionnaire from previous of research as adaptation process to create the elements and further the strength by validity testing via experts of study. A number of samples selected as respondents are 222 from 250 number of population. Referring on research objective achievement, the number of items has been changed after validity test. For the reliability test, all items after validity test selected are accepted. The confirmatory factor analysis has been shown that two items from communication elements and two items from supervision have been rejected. The final decision numbers of items in communication elements are eight, while in supervision are 12 items.
\end{abstract}

Keywords: Trainee Doctor, Medical Learning, Supervision, Communication, Confirmatory Factor Analysis (CFA).

\section{Introduction}

The communication and supervision is an importance element for the era of the medical training and learning process. The importance of communication as a collaboration between two people involved (Allen, Petrisek \& Laliberte, 2010). Based on Al Khalid and Ar Farid (2010), communication only able be carriage and received via communication. The practitioner also necessities have a good and clear of communication in order to attainment accurate of an information. Occasionally, the erroneous of communication may perhaps affect the information position. According in medical field, the incorrect information delivering effect numerous problems and perchance grounds the accident ensues at hospital (Ardnt et al. 2007). A single the factual and accurate information need to deliver with listener. Previous, several mistakes occur to patients on ward resources from trainee doctor problem during communication (Aspegren \& Lonberg-Madsen, 2005). The precise people as a communicator correspondingly desires. In medical phenomenon, trainee doctor mostly construct relationship with supervisor. Although, the learning process frequently necessity the supervisor facilitating and supervision such as in working experience sharing and supervision in practical was doing (Azer, 2007). Consequently, this research references approximately the supervision too. The main purpose from this research is developing an instrument in communication and supervision of clinical. Moreover, for elements development, the previous of research as well discussion in order to create the elements strongly and appropriate in future research uses.

\section{Communication Clinical}

The communication of trainee doctor is a social interaction conceded by trainee doctors by way of day-to-day foundation speech at the hospital (Dobie, 2007). That variety of communication ensues amongst trainee doctors and trainee doctor with supervisors, specialist doctors or patients while in medical learning process (Fellowes, Wilkinson \& Moore 2004). 
Other than these, communication carried out by trainee doctors an essentially as medical nature (Williams, 2002). The style of communication carried out is also different (Mc Leod et al., 2003). According to Lane and Rollnick (2007), the style of communication carried out requirement deliver a message that is related to medical learning. In addition, to approach in a way related to it as well. The communication between trainee doctors and supervisors are differing from the style of communication with patients (Bylund et al. 2010). Trainee-supervisor communication also tends to be conducted in a more formal style, as opposed to communication between trainee doctors (Bensing et al., 2008). That is because supervisors are the ones responsible for evaluating and observing a trainee doctor's potential while in medical learning (Lane \& Rollnick, 2007).

Trainee doctors tend to communicate verbally than using other forms of communication. However, Reichelt et al. (2009) stressed that the presentation must be appropriate to the situation and the environment. There are instances someplace the situation and the environment does not permit verbal communication. For instance, when working in the Intensive Care Unit (ICU), trainee doctors are more inclined to use non-verbal and sign language as primary forms of communication to guarantee patients, especially those under intensive care are not disturbed (Zaharias, Piterman \& Liddell 2013). If disturbed, patients can be aggravated and might disrupt the healing process. Therefore, trainee doctors need to be creative in communicating under these conditions. Everyone, notably the Ministry of Health, who works closely with trainee doctors need to work together to improve communication skills. The Malaysian Ministry of Health strives to achieve the highest standard of communication skills among trainee doctors. A good communication skill is a good indicator of a trainee doctor's confidence in his skills and abilities as trained personnel during the course of medical learning.

\subsection{The Importance of Trainee Doctor Communications}

Communication serves as the driver of interaction that forms a collaborative between trainee doctors and other individuals during the course of the medical learning. Collaboration in interaction can be carried out through discussion and idea sharing via communication (Brugge et al., 2009). Through discussion, trainee doctors will be able to exchange ideas and question each other's opinions (Bylund et al., 2010). Idea exchange and critique will produce the best results in learning through housemanship. The best results are shown to be creative and critical, borne by the process of idea exchange and critical thinking (Al Klalid \& Ar Farid, 2010). Creative ideas and critical thinking is exhibited through a trainee doctor's confidence in his communication. Abdul Majeed, Habib and Rafiqul (2011) also mentioned creativity and critical thinking into their study. They stressed on the importance of communication because how a trainee doctor interacts with people around him is a good indicator of his level of knowledge. A quiet trainee doctor who tends to shy away from interaction is almost always someone who is not very knowledgeable. This view is similar to Patel (2010) who stated that trainee doctors are only able communicate in a systematic manner when they are knowledgeable about it.

Limitations are the most common obstacles facing trainee doctors in interacting with patients (Ledingham \& Dent, 2011). The traditional concept of communication proves to be one of the problems facing trainee doctors. Traditionally, diagnosis is carried out with a two-way communication between the doctor and the patient (Wallace et al., 2001). Nowadays, there are various concepts of communication that are modern and technology-based that allows communication to be carried out easier. For example, Electronic Medical Record (EMR) can be used by doctor prevent information overload. Information overload happens when there is too much information obtained from an interaction that leads to difficulties in filtering it (Williams, 2002). By using modern concepts in communication, trainee doctors can carry out their medical learning efficiently and systematically.

Modern technology and equipment's are able to aid communication. However, technology can also hinder it (Kim and Kim, 2009). This is due to the fact that doctors could be too preoccupied with Email, SMS, as well as a plethora of applications such as Facebook, What Sapp, We chat and Line which could lead to various problems during communication. Face-to-face communication is always better than virtual interaction. Misinformation and information inadequacy could be caused by using modern applications (Hayes et al., 2009). For instance, the Nottingham City Hospital in Nottingham, UK insists on face-to-face interactions even though they are working in a high-tech environment (Willis, Jones \& Oneill 2003). This goes in line with their vision and mission to be a tolerant and friendly institution.

\subsection{Theory and Communication System for Trainee Doctors}

Proper approach to communication is important in medical learning studies. Therefore, trainee doctors need to be wise in communicating with others (van Ruler et al., 2005). Wisdom in communication can be seen from a trainee doctor's ability in choosing the right theory and communication model for the learning process (Rogers et al., 2003). For instance, a 
trainee doctor has to have discussion skills in order to engage in fruitful discussion to produce ideas with creative and thinking skills. Brown, Stewart and Ryan (2003) stated that discussion is a group-oriented communication. A group discussion may be participating by members from various societal backgrounds with their own opinions to be made heard (Veil \& Hausted, 2002). Therefore, the right theory and model must be used to ensure that communication can be streamlined and made easier.

\subsubsection{Groupthink Theory}

Groupthink is a theory that indirectly affects communication during medical learning. However, it does not contribute significantly to the medical learning (Curtis, Tzannes \& Rudge, 2011). In contrast, supervisors put this theory in high regard. This theory is used predominantly by supervisors because they act as individuals that communicate in a one-way manner as opposed to a two-way communication (Salamonsen, 2012). This shows that the groupthink theory incorporates a one-way communication.

The operationalization of formation of conflict in communication happens because of the negative feelings that a supervisor harbours for the trainee doctor (Gionta et al., 2005). They think that they have more experience and knowledge in the medical field (Hulsman et al., 2002) therefore trainee doctors are told to just listen to their supervisor during medical learning. Besides the supervisor, the groupthink theory also applies to trainee doctors that have been in medical learning longer that their junior counterparts (Suter, 2009). Mulapo and Muula (2010) stated that even though trainee doctors have been in medical learning for a longer period of time, they are still relatively inexperienced and lack in some aspects, skill-wise. The shortcomings arise from problems in utilizing their knowledge and skills (Brown \& Bylund, 2008). Rider and Keefer (2006) on the hand believe that knowledge is the essence of communication, because confidence and ease in communication relies on a firm grasp on the topic at hand. Even Shillings, Jenkins and Fallowfield (2003) pointed out that the passive and quiet trainee doctor is most probably not very knowledgeable in his field. In essence, the groupthink theory should not be allowed to be prevalent among trainee doctors because they are relatively less knowledgeable and skifful. The groupthink theory is not suitable for interactions between trainee doctors and supervisors as well as senior trainee doctors. However, the theory would make trainee doctors dominant when used in interactions with patients (Tavakol et al., 2006).

\subsubsection{The PACE System (Presenting, Asking, Checking, Expressing)}

The PACE system is another approach in communication that is frequently used by trainee doctors in the course of medical learning. PACE refers to a communication system that aids trainee doctors in their medical learning based on the principles of achievements (Grant \& Robling, 2006). The PACE System was developed by three experts Cegala, Marinelli and Post (2002) and embraces the concepts of Presenting, Asking, Checking and Expressing. In turn, trainee doctors are encouraged to use PACE consistently in a sequential manner, to clarify the phases of communication (Piette et al., 2005). Heaven (2001) and Bereiter and Scardamalia (2004) outlined the process of applying this approach to communication: application starts with Presenting $(P)$ followed by Asking $(A)$, Checking $(C)$ and ended with Expressing $(E)$. When these phases in communication are carried out systematically, learning during medical learning will be much easier. The best way to achieve maximum medical learning is through discussion and presentations based on the PACE System approach (Bleakley 2006; Kumar \& Clark 2005).

The first step is Presenting $(P)$. Presenting is carried out by trainee doctors to showcase their level of knowledge and capabilities during medical learning (Ratzan, 2010). Through presenting, trainee doctors will explain theories, concepts and comprehension in detail of the subject that they are studying (Feng et al., 2011). Explanations need to be in depth to show that a deep understanding has been achieved by the presenter. Therefore, good communication skills are crucial to ensure the presentation is up to standard (Cegala et al., 2007). Supervisors are also observing the presenter for the quality of the communication while they are presenting (Puska, 2010). Diligence, confidence and wisdom are elements that must be present in a trainee doctor's presentation to ensure credibility (Frieden \& Koplan, 2010). If there are any questions that the supervisor has based on the presentation that will be the start of an active interaction session in the next stage: Asking.

Asking is the second stage of PACE system. This stage is where questioning and answering takes place. (Jerant et al., 2009). To succeed in this stage, two-way communication is essential (Richard 2010). Two-way communication is established between the trainee doctor and the supervisor. The supervisor acts as the enquirer, while the trainee doctor answers these questions (Brown et al., 2007). Trainee doctors must answer all questions posed by the supervisor. Supervisors will gauge the comprehension and knowledge about the medical learning of the trainee doctors based on 
their answers (Brown \& Bylund, 2008). A confident and proper answer is a good indicator that the trainee doctor is very capable and knowledgeable; confusion and inability to answer often indicates an incapable trainee doctor (Jones, Mcardle \& O'Neill, 2001). This proves that communication can reveal a person's level of knowledge and wisdom (Brown et al., 2008). If the supervisor spots a mistake, he will assess the severity and determine what needs to be fixed. This is where the third stage, checking, takes place.

Checking is a stage where trainee doctors' knowledge will be improved through one-way communication. Improvements to the trainee doctors' knowledge can be carried out by information sharing as well as knowledge and idea sharing by the supervisor. Bylund et al. (2009) stated that the importance of the one-way communication at this stage is to make the supervisors' message go through easier. At this stage, supervisors will give comments and correct mistakes and trainee doctors need to accept the corrections and critique from their supervisor. Bylund et al. (2009) also explained that trainee doctors need to put their passive attitudes aside and be committed and comprehensive, in order to improve the learning process during medical learning. The stage where supervisors and trainee doctors have a one-way communication is called Expressing. At this stage, trainee doctors are given the chance to explain the idea of their presentation at the Presenting stage. This is where confidence plays a major role to empower trainee doctors to defend and justify their presentation (Epstein \& Street, 2007).

\section{Supervision Clinical}

According to Cate and Durning (2007), clinical supervision responsibility by supervisor to trainee doctor has become a good practitioner of medical. Contains and context of supervision clinical prerequisite comprise the scientific, clinical and concerning learning process accomplishments (Frank \& Snell, 2010). In Malaysia approach, the Ministry of Health provide the guidelines of supervision in order to encourage the standardized of achievement was occur. The supervisor of background such as the historical of experiences services too as a compulsory following. Amongst the standards is needed such as knowledge, the experiences the history in supervision successful. The respectable relationship might escape the conflict or problem among supervisor and supervises. Besides, the supervisor can't develop an unfairness or bias while in supervision. According to Scott and Vanessa (2010), bias might affect the trainee doctor performance during learning process. Only more than a few of them can achieved and performance well. The upright performer is persons the supervisor likes to share their ideas. In contrast, the other trainee doctor individuals disregard by supervisor conceivably demotivated and receiving poor of performance while in medical learning. Consequently, the supervision essentials determined the objective and outcome of finding is equilibrium. As well, the trainee doctor achieved the gratified performance.

\subsection{The Importance of Trainee Doctor Supervision}

Referring on Wanggren, Pettersson and Gemzell-Danielsson (2010), the supervision needs conducted by experiences and knowledgeable person. The experience and knowledge encourage trainee doctor realise, innovate and development of a philosophies. Even though, trainee doctor need support themselves and create their own competence. It is because the supervisor role as a mentor and facilitator (Ladany \& Melinkoliff, 2009). For example, in Malaysian phenomenon during supervision process, the supervisor needs to assist trainee doctor in Tagging activities. The Tagging activities are one of syllabus in trainee doctor learning process especially for night duty intensive. Normally, Tagging will happenings since two weeks only. As long as the Tagging process on going, trainee doctor qualify to catch numerous information and do the duties with accurate manner.

The supervisor requisite to deliver modest but meaningful of learning process contain for ensure the trainee doctor may achieved the precise of learning. The supervisor attitude also influenced the trainee doctor performance. Relaxing, escape the pressure environment and generate the brilliant ideas is compulsory. The trainee doctor needs to sophistication by supervisor. Supervisor role changer for trainee doctor for develops themselves. Amongst develop needed such as knowledge, skill and attitude in higher level of performance.

\subsection{Theory and Model of Supervision Clinical}

Even though this research concentration on the development of supervision clinical instrument in survey contain, the researcher review several of theory and model. The theory and model review as an effort to contribute the appropriate items for each element. According to Ghosh and Ross (2009), the theory and model as foundation to develop idea and prepare improvement in supervision of clinical. Consequently, the determination of theory and model would be practice 
prerequisite to be occupied identifying. The weakness and the strength of theory and model had chosen its significance and prominence. Furthermore, implication and contribution of theory and model selected requests to be accomplishment approximately innovative for produce an innovation and impervious the movement of paradigm achieved.

\subsubsection{Bloom Taxonomy Theory}

The Bloom Taxonomy applied in clinical supervision learning process. The role of this theory as a learning and teaching of designed and move up the discipline of trainee doctor (Bleakley, 2006). An implication of applied this theory is construct discipline amongst trainee doctor during medical learning process. The theory having five stages in supervision approaches of learning process. The stages are Recall, Analysis, Comparison, Inference and Evaluation (Ferguson, 2005). First stage is Recall. Recall stage is an accomplishment by supervisor to guide trainee doctor prepares reflection in knowledge and skill for practice in learning process (Kreps, 2012). The second stage is Analysis that supervisor evaluate the knowledge and skill applied by trainee doctor either appropriate or apposite. Then, supervisor tries to conversation something almost the proper knowledge and skill application in stage three (Comparison). By the stage number four (Inference), the supervisor prepares an observation concerning the chosen of trainee doctor in knowledge and skill selection. Lastly, the final stage (Evaluation) is imperative to confirm the effectiveness of trainee doctor knowledge and skill application.

\subsubsection{Traditional Scientific Supervision Theory}

This theory is recurrently practice in medical learning process. The perception of this theory as a group of individual need controlled. However, this theory has negative effect. The negative occur because the relationship between trainee doctor and supervision is far. The practically of this theory is supervisor as a communicator and trainee doctor as listener only. Trainee doctor need to listen and follow all supervisor instruction. The learning method style appears here is pedagogy style. Although, according to Malangoni et al. (2005), the compensations of application this theory in medical learning is elude some mistaken from trainee doctor. Furthermore, the trainee doctor possibly increases the highest of achievement recovered than before. Moore (2008) support the statement because he found the systematically of learning ethic is consistency and greatest. Each step and phase of learning only conducted by supervisor and trainee doctor as a supporter or implements the supervisor instructions. However, the trainee doctor perchance partaking matter because after the learning process, they cannot accomplish well without their supervisor guidance and facilitate.

\subsubsection{Human Relationship Supervision Theory}

The principle of this theory is a good relationship among supervisor and trainee doctor. Furthermore, D'Eon (2006) declaration a good relationship among supervisor and supervisee might have a good environment in medical learning process. It is because, the trainee doctor impression a great of satisfaction based on participant, involvement and contribution of opinion towards particular of learning process (Balmer et al., 2008). The theory application charitable occupied confidential of supervisor to trainee doctor ability and inability. Trainee doctor is freedom to control their own learning style. Although, the learning style prerequisite acquire guidance and check by supervision ethic before the implementation will be performance.

\section{Research Objective}

(1) To identify the trainee doctor communication and supervision element based on value from Alpha Cronbach and the validity tested.

(2) To identify the trainee doctor communication and supervision element based on value from Confirmation Factor Analysis (CFA) tested.

(3) To investigate the items need rejected besides choose the needed items in communication and supervision elements. 


\section{Research Methodology}

\subsection{Location of Study}

This research was conducted at two hospitals in Johor of Malaysia. The two hospitals conduct the learning process amongst medical students after past at universities or medical school as medical graduated. Nevertheless, they are still not as medical practitioners yet. The trainee doctors necessity to undergo in medical learning process since two years (minimum). The name of medical learning amongst trainee doctor is housemanship. Only the trainee doctor past in universities or medical school and having a certificate as medical graduation, is worthy to undergo on medical learning in housemanship program. This research selects location of research in Johore Bahru, Malaysia. The two hospitals has been selected is Sultan Ismail, Hospital of Johore Bahru Johor, Malaysia and second is Sultanah Nora Ismail, Hospital of Batu Pahat Johore, Malaysia.

\subsection{Instrument}

This research designed statistical and data collection uses survey by questionnaire distribution. The first of instrument development produce by previous research and support by theoretical and model approaches. For the first instrument development, researcher selects several of previous questionnaires. The selected of questionnaire necessity be relevant with communication and supervision area. Amongst the previous research have been selected are, Mc Gill, Van der Vleuten and Clarke (2011), Whitehouse, O' Neill and Dornan (2006) and Todres, Stephenson, and Jones, (2007). As a while as the instrument develop, researcher do three type of validity testing in order to achieved the appropriate items. The three of validity test are face validity, construct validity and contain validity. The face validity has been implementation by experts checking. Experts check on every single of items and giving evaluation, comment and suggestion. The construct validity does by researcher. The researcher constructs based on main and minor area of research and select the suitable items to fulfil in that research. Only the suitable items able are chose. The contain validity is remarks items necessary to matching with the elements filled. The communication and supervision in medical learning contain necessity regarding the trainee doctor needs while in medical learning purposely only.

\subsection{Scope, Population and Sampling of Research}

Research scopes select the second year of trainee doctor during medical learning (housemanship). The number of population is 250 of trainee doctor. Referring on Kreiji and Morgan (1970) table, the number of sampling is 148. However, for accomplishment strengthened of research finding, researcher have been done distribute 245 number set of questionnaire. The method of sampling selected is simple random sampling. Based on output of questionnaire returned, 222 number of questionnaire successful collected.

\section{Finding and Discussion}

\subsection{Objective 1: The Validity and Reliability of Research}

The research use validity of test to get the appropriate items and elements for instrument development. Contain validity function to test contain of adaptation previous questionnaire. Content validity also testing by previous research instrument and have been done test as empirical in the research (Babbie, 2002). The main factor need to prepare in content validity is research scope. In this research, communication and supervision is the main scope need to decide in instrument development. Referring on previous research, there are 28 number of set instrument having closed similarity. However, only numerous questions were selected based on suitability on research planning in the future. The research arrangement for future expectation is trainee doctor learning. As a result, the contain need about communication and supervision clinical of trainee doctor while in learning process.

According to previous research, there are 28 number of question having the communication elements. However, only 7 number of question selected as items in communication elements. Besides that, for the supervision elements having 25 number of question in the totally actual all previous of instrument. Nevertheless, only 7 numbers of items selected to fulfil the supervision elements. The number of final items selected items referring on Table 1.

Researcher also does the three of validity testing. First, the face validity makes by expert lecturer in the field of study selected. A several number of lecturer selected having experiences, knowledge and experiences in field of study. 
Amongst the experts come from four research university of Malaysian country such as University of Malaya, University of Putra Malaysian, National University of Malaysian and Technology University of Malaysian. All experts selected are a professor and associate professor title was selected.

Table 1: Face Validity Testing Before and After Experts Checking

\begin{tabular}{|l|c|c|}
\hline Elements & \multicolumn{2}{|c|}{ Number of Items during Face Validity Process } \\
\hline Communication & Before & After \\
\hline Supervision & 7 & 10 \\
\hline
\end{tabular}

Table 1 have been showed that expert' critique, give opinion and suggestions about the items. Among the critique, opinion and suggestions from experts are listed as below:

a. There are several of items repetition and difficult to understand

b. There are several of items having have two meaning and more in one items

c. There are several items having clash of phases.

d. Expert's suggestion is the items contained need to have the housemanship, medical and clinical terms in word and phases.

e. The researcher need to change and choose the best word, phases, term and throw away the not suitable of items.

Table 2: Alpha Cronbach of Value

\begin{tabular}{|c|c|c|c|c|}
\hline \multicolumn{5}{|c|}{ Items } \\
\hline \multicolumn{3}{|l|}{ Communication } & \multirow{2}{*}{\multicolumn{2}{|c|}{$\begin{array}{c}\text { Supervision } \\
0.832\end{array}$}} \\
\hline Totally Items of Alpha Cronbach Value & \multicolumn{2}{|c|}{0.653} & & \\
\hline \multirow[t]{14}{*}{ Alpha Cronbach Value if Selected Item Deleted: } & $\mathrm{km} 47$ & 0.612 & py 57 & 0.819 \\
\hline & $\mathrm{km} 48$ & 0.604 & py 58 & 0.811 \\
\hline & $\mathrm{km} 49$ & 0.601 & py 59 & 0.809 \\
\hline & $\mathrm{km} 50$ & 0.617 & py 60 & 0.807 \\
\hline & km 51 & 0.623 & py 61 & 0.807 \\
\hline & $\mathrm{km} 52$ & 0.638 & py 62 & 0.812 \\
\hline & $\mathrm{km} 53$ & 0.717 & py 63 & 0.808 \\
\hline & $\mathrm{km} 54$ & 0.598 & py 4 & 0.808 \\
\hline & km 55 & 0.602 & py 65 & 0.812 \\
\hline & $\mathrm{km} 56$ & 0.656 & py 6 & 0.819 \\
\hline & & & py 7 & 0.843 \\
\hline & & & py 68 & 0.845 \\
\hline & & & py 69 & 0.843 \\
\hline & & & py 70 & 0.845 \\
\hline
\end{tabular}

After complete the validity of items, researcher continues on reliability testing to find out alpha cronbach value. Based on Table 2, the finding of reliability test has been showed the value of alpha cronbach. The communication value is 0.653 lowest than supervision value is 0.832 . Besides that, researcher attaches the alpha cronbach value if certain item was deleted. For example, based on Table 2 has been shown from 10 items in communication elements, only one item (Questions 54) if deleted change the alpha value become weak. So questions 53 are very important. For others item, question numbers 53 affect the elements from moderate too good of that item deleted. But, researcher has decided proceeds all the items and without dropped any item. Table 2 also has been shown the supervision items of alpha cronbach value. All item get very good position either any questions is dropped. So, researcher has decided zero of items in supervision elements are drop. All items are selected either in communication or supervision elements.

\subsection{Objective 2 and 3 Finding:}

This research was used the confirmatory factor analysis (CFA) for getting best of items as question in set of questionnaire later. According to Byrne (2010), the researcher uses CFA identify the suitability and compatibility the set of items in elements. Besides, CFA also use for identify the level of strength in Model Fit (Bentler, 1990). There are several factor influenced the strength of Model Fit in CFA. Amongst factors are CMIN/DF $\leq 3, R M R \leq 0.08, C F I \geq 0.9, G F I \geq 0.9$ and RMSEA $\leq 0.08$. Besides that, the researcher also sees the Modification Indices value, refer on the highest of e value to 
combine in CFA Figure. Next, when the condition is fulfilling, the researcher refer on estimates value and in standardized regression weight in order to delete the value below on 0.3. After that, the researcher repeats the same method based on CFA analysis. If all condition have been done fulfil, the items in elements is accepted (Krehbiel, 2004).

\subsubsection{The Communication Elements Development Using by Confirmation Factor Analysis Testing}

Table 3 has been showed the Confirmatory Factor Analysis for communication elements. The researcher illustrates the elements figure based on Figure 1. All items included in that figure. Researcher has been done do four analysis before getting the Model Fit. The first analysis has been shown model are not fit because the value is $X^{2} / d f=8.752, R M R=0.197$, $\mathrm{CFI}=0.705, \mathrm{GFI}=0.790$, RMSEA $=0.187$. Referring in modification indices value, items of question 54 and question 55 is highest among other and need to connect in CFA Model. After the connection, second analysis has been done. The second analysis has been showed the model still not fit because the value is $X^{2} / d f=3.922, R M R=0.146, C F I=0.892$, $\mathrm{GFI}=0.898$, RMSEA $=0.115$. The second analysis has been showed the modification indices highest value is question 56 and question 54 and need to connect. After the connection, researcher does the third analysis and the models are still not fit. The value is $X^{2} / \mathrm{df}=3.944, \mathrm{RMR}=0.139, \mathrm{CFI}=0.894, \mathrm{GFI}=0.899, \mathrm{RMSEA}=0.115$. Therefore, researcher refers to modification indices value and sees the higher of two questions. The highest value in modification indices are 42.945 (question 56 and 54). The two of questions need to be connected. Then, researcher does the fourth analysis. The fourth analysis has been showed the value is $\chi^{2} / d f=1.897, R M R=0.086, C F I=0.896, G F I=0.950, R M S E A=0.064 . X^{2} / d f=1.897$, $\mathrm{RMR}=0.086, \mathrm{CFI}=0.896, \mathrm{GFI}=0.950, \mathrm{RMSEA}=0.064$. Based on fourth analysis, only 3 of the data fulfil the model it but RMR and CFI values still not fulfil the model fit condition. So, researcher refer on modification indices and found the highest value is 12.659 (Question 53 and 54 need to be connection) and run the fifth analysis. Fifth analysis have been show see the value is $\mathrm{X}^{2} \mathrm{df}=1.873, \mathrm{RMR}=0.080, \mathrm{CFI}=0.971, \mathrm{GFI}=0.953, \mathrm{RMSEA}=0.063$.

Table 3: Analysis for Communication Element Using Confirmation Factor Analysis

\begin{tabular}{|c|c|c|c|c|}
\hline \multicolumn{5}{|c|}{ Model Fit Value } \\
\hline First Analysis & \multicolumn{4}{|c|}{$X^{2} / \mathrm{df}=8.752, \mathrm{RMR}=0.197, \mathrm{CFI}=0.705, \mathrm{GFI}=0.790, \mathrm{RMSEA}=0.187$} \\
\hline Second Analysis & \multicolumn{4}{|c|}{$x^{2} / \mathrm{df}=3.922, \mathrm{RMR}=0.146, \mathrm{CFI}=0.892, \mathrm{GFI}=0.898, \mathrm{RMSEA}=0.115$} \\
\hline Third Analysis & \multicolumn{4}{|c|}{$\mathrm{X}^{2} / \mathrm{df}=3.944, \mathrm{RMR}=0.139, \mathrm{CFI}=0.894, \mathrm{GFI}=0.899, \mathrm{RMSEA}=0.115$} \\
\hline Fourth Analysis & \multicolumn{4}{|c|}{$\mathrm{X}^{2} / \mathrm{df}=1.897, \mathrm{RMR}=0.086, \mathrm{CFI}=0.896, \mathrm{GFI}=0.950, \mathrm{RMSEA}=0.064$} \\
\hline Fifth Analysis & \multicolumn{4}{|c|}{$X^{2} / d f=1.873$, RMR $=0.080$, CFI $=0.971$, GFI $=0.953$, RMSEA $=0.063$} \\
\hline Sixth Analysis (After Deleted Item 56) & \multicolumn{4}{|c|}{$\mathrm{X}^{2} / \mathrm{df}=1.863, \mathrm{RMR}=0.072, \mathrm{CFI}=0.978, \mathrm{GFI}=0.957, \mathrm{RMSEA}=0.060$} \\
\hline Sixth Analysis (After Deleted Item 54) & \multicolumn{4}{|c|}{$\mathrm{X}^{2} / \mathrm{df}=1.860, \mathrm{RMR}=0.068, \mathrm{CF}=0.993, \mathrm{GFI}=0.963, \mathrm{RMSEA}=0.050$} \\
\hline \multicolumn{5}{|c|}{ Modification Indices Value (Analysis) } \\
\hline Item & First & Second & Third & Fourth \\
\hline km51 $\leftarrow$ km52 & 8.439 & 8.431 & 8.439 & 8.398 \\
\hline km52くkm51 & 6.922 & 6.919 & 6.390 & 6.896 \\
\hline $\mathrm{km} 53 \leftarrow \mathrm{km} 54$ & 12.790 & 12.672 & 13.599 & 12.659 \\
\hline $\mathrm{km} 53 \leftarrow \mathrm{km} 55$ & 10.920 & 10.770 & 10.764 & 10.780 \\
\hline $\mathrm{km} 53 \leftarrow \mathrm{km} 56$ & 7.517 & 7.442 & 7.431 & 7.370 \\
\hline $\mathrm{km} 54 \leftarrow \mathrm{km} 53$ & 11.451 & & & \\
\hline $\mathrm{km} 54 \leftarrow \mathrm{km} 55$ & 119.597 & & & \\
\hline $\mathrm{km} 54 \leftarrow \mathrm{km} 56$ & 44.606 & & & \\
\hline $\mathrm{km} 55 \leftarrow \mathrm{km} 53$ & 9.756 & & & \\
\hline $\mathrm{km} 55 \leftarrow \mathrm{km} 54$ & 119.339 & & & \\
\hline $\mathrm{km} 55 \leftarrow \mathrm{km} 56$ & 58.983 & 16.609 & 28.721 & \\
\hline km56 $<\mathrm{km52}$ & 5.684 & 5.678 & 5.866 & 4.770 \\
\hline $\mathrm{km} 56<\mathrm{km} 53$ & 9.388 & 9.383 & 7.977 & \\
\hline $\mathrm{km} 56<\mathrm{km} 54$ & 42.931 & 42.945 & & \\
\hline $\mathrm{km} 56 \leftarrow \mathrm{km} 55$ & 57.485 & 57.502 & 56.375 & \\
\hline \multicolumn{5}{|c|}{ Estimates Value } \\
\hline $\mathrm{km} 47$ & & 0.554 & km52 & 0.319 \\
\hline km48 & & 0.611 & km53 & 0.387 \\
\hline $\mathrm{km} 49$ & & 0.786 & km54 & 0.102 \\
\hline km50 & & 0.801 & km55 & 0.350 \\
\hline km51 & & 0.408 & km56 & 0.015 \\
\hline
\end{tabular}

All the data have been done fulfil the model fit in fifth analysis. Figure 2 has been showed the completed Figure after Model Fit fulfilled. After the model fit are fulfil, researcher refer on estimates value to ensure all factor loading value above on 0.30 . The finding has been showed only two items getting lower that 0.3 that is item question 56 and 54 . The first step, 
researcher select the lowest value that is 0.015 (Question 56) and deleted in the figure. After that, researcher run again the analysis and the finding value is $\chi^{2} / d f=1.863, R M R=0.072, C F I=0.978, G F I=0.957, R M S E A=0.060$. Next, researcher move toward back to the estimates value to take the second lowest of value. The second lowest of value is $0.102(\mathrm{~km} 54)$ and deleted the item in the Figure. Referring on Figure 3, Researcher has been shown the selected of items in Model Fit. The entire item selected already fulfils the Model Fit Condition except the question 54 and 56 in communication elements.

Figure 1: Communication Elements in CFA

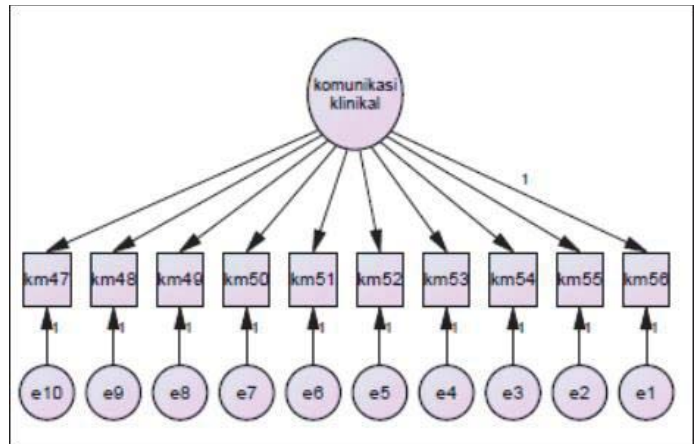

Figure 2: Communication Elements in Model Fit Condition Fulfilled

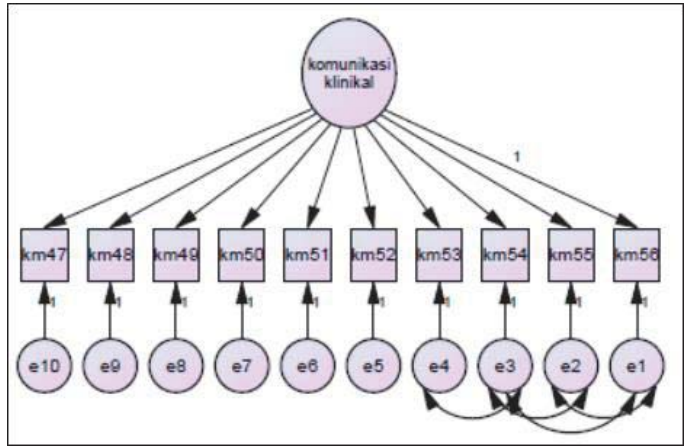

Figure 3: Final Selected of Communication Elements in Model Fit

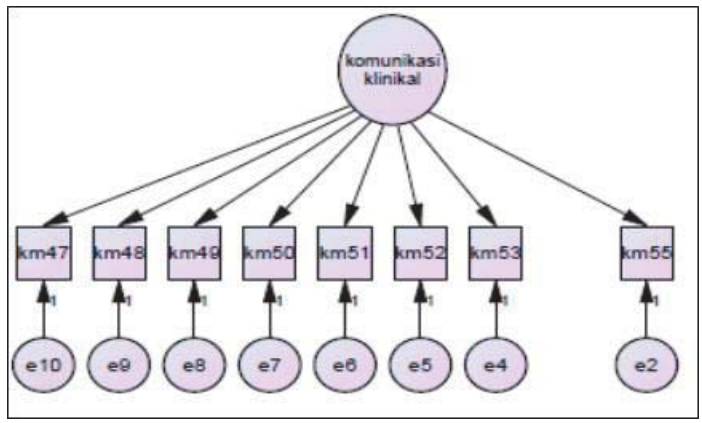

\subsubsection{The Supervision Elements Development Using by Confirmation Factor Analysis Testing}

Table 4 has been showed the Confirmatory Factor Analysis for supervision elements. The researcher illustrates the elements figure based on Figure 4. All items included in that figure. Researcher has been done do seven analysis before getting the Model Fit. The first analysis has been shown model are not fit because the value is $X^{2} / \mathrm{df}=10.648, \mathrm{RMR}=0.206$, $\mathrm{CFI}=0.694 ., \mathrm{GFI}=0.719$, RMSEA=0.209. Referring items of question 68 and question 67 need to connect because the value of modification indices highest among (164.903). Second analysis has be done and shown that the model still not fit because the value is $X^{2} / d f=6.789, R M R=0.144, C F I=0.819, G F I=0.779$, RMSEA $=0.162$. The second analysis has been showed the modification indices highest value is 140.828 (Question 56 and Question 54). Third run of data analysis has been done but models only fit on RMR and CFI but others is not. The third analysis has been shown value is $X^{2} / \mathrm{df}=3.889$, RMR=0.066, CFI=0.911, GFI=0.844, RMSEA=0.114. The modification indices value for third analysis is 28.999 for question 65 and 66. 
The two of question 65 and 66 need to be connect in CFA Figure. Then, the analysis does again but still in fourth analysis having the same of status alike in third analysis. The values is $X^{2} / \mathrm{df}=3.332, \mathrm{RMR}=0.063, \mathrm{CFI}=0.929, \mathrm{GFI}=0.867$, RMSEA $=0.103$. The analysis runs until seventh analysis. Among the items having highest and connected in CFA Figure is among question 58 and 57(21.688), among question 58 and 65 (7.783) and among question 64 and 65 (6.534). All items in two questions are connected based on the analysis in Model Fit achieving. The question are connected because the Model fit are still not fit in fifth analysis $\left(X^{2} / d f=2.810, R M R=0.061, C F I=0.946, G F I=0.886, R M S E A=0.091\right)$. In the fifth

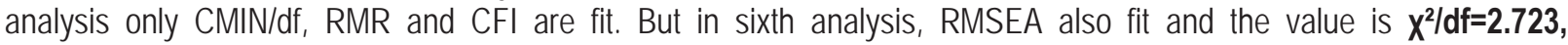
RMR $=0.060, \mathrm{CFI}=0.949, \mathrm{GFI}=0.889$, RMSEA $=0.078$. The complete of model fit in fulfil condition appear in seventh of analysis whereby all data fit and fulfil the model fit of condition. The value is $X^{2} / d f=2.549, R M R=0.059, C F I=0.955$, GFI $=0.901$, RMSEA $=0.079$. The figure 5 has been shown that all condition in model fit is fulfilled and the connection of questions is required to be the fit of model.

After that, the factor loading in estimates value is still need to alert. Researcher see only two items having the lower than 0.30 factor loading value. So, the two item need to be drop one by one based on the lowest value. The lowest value is 0.026 (Question 69). After dropping the question 69, researcher run again the CFA analysis for get the best value in model fit. The value getting are $X^{2} / \mathrm{df}=\mathbf{2} .818, \mathrm{RMR}=\mathbf{0 . 0 4 7}, \mathrm{CFI}=\mathbf{0 . 9 5 1}, \mathrm{GFI}=\mathbf{0 . 9 0 0}$, RMSEA=0.079. Next, researcher dropped that one more question having below that 0.30 factor loading. The question is 68 and the values are 0.048 . After the dropping, researcher achieved the final of model fit is $X^{2} / d f=2.818, R M R=0.047, C F I=0.951, G F I=0.900$, RMSEA $=0.074$. Finally, researcher have been concluded that two question is dropped in supervision elements. The two of question is 68 and 69. Based on figure 6 has been shown the CFA illustrate Figure that is two of communication items has been deleted because having the factor loading below than 0.30 .

Table 4: Analysis for Supervision Element Using Confirmation Factor Analysis

\begin{tabular}{|c|c|c|c|c|c|c|}
\hline \multicolumn{7}{|c|}{ Model Fit Value } \\
\hline First Analysis & \multicolumn{6}{|c|}{$X^{2} / \mathrm{df}=10.648, \mathrm{RMR}=0.206, \mathrm{CFI}=0.694 ., \mathrm{GFI}=0.719, \mathrm{RMSEA}=0.209$} \\
\hline Second Analysis & \multicolumn{6}{|c|}{$\mathrm{X}^{2} / \mathrm{df}=6.789, \mathrm{RMR}=0.144, \mathrm{CFI}=0.819, \mathrm{GFI}=0.779, \mathrm{RMSEA}=0.162$} \\
\hline Third Analysis & \multicolumn{6}{|c|}{$X^{2} / \mathrm{df}=3.889, \mathrm{RMR}=0.066, \mathrm{CFI}=0.911, \mathrm{GFI}=0.844, \mathrm{RMSEA}=0.114$} \\
\hline Fourth Analysis & \multicolumn{6}{|c|}{$X^{2} / d f=3.332$, RMR $=0.063, \mathrm{CFI}=0.929, \mathrm{GFI}=0.867, \mathrm{RMSEA}=0.103$} \\
\hline Fifth Analysis & \multicolumn{6}{|c|}{$\mathrm{X}^{2} / \mathrm{df}=2.810, \mathrm{RMR}=0.061, \mathrm{CFl}=\mathbf{0 . 9 4 6}, \mathrm{GFI}=0.886, \mathrm{RMSEA}=0.091$} \\
\hline Sixth Analysis & \multicolumn{6}{|c|}{$\mathrm{X}^{2} / \mathrm{df}=2.723, \mathrm{RMR}=0.060, \mathrm{CFI}=0.949, \mathrm{GFI}=0.889, \mathrm{RMSEA}=\mathbf{0 . 0 7 8}$} \\
\hline Seventh Analysis & \multicolumn{6}{|c|}{$\mathrm{X}^{2} / \mathrm{df}=2.549, \mathrm{RMR}=0.059, \mathrm{CFI}=0.955, \mathrm{GFI}=0.901, \mathrm{RMSEA}=0.079$} \\
\hline Eighth Analysis (After Deleted Item 69) & \multicolumn{6}{|c|}{$\mathrm{X}^{2} / \mathrm{df}=2.818, \mathrm{RMR}=0.047, \mathrm{CFI}=0.951, \mathrm{GFI}=0.900, \mathrm{RMSEA}=0.079$} \\
\hline ninth Analysis (After Deleted Item 68) & \multicolumn{6}{|c|}{$\mathrm{X}^{2} / \mathrm{df}=2.818, \mathrm{RMR}=0.047, \mathrm{CFI}=0.951, \mathrm{GFI}=0.900, \mathrm{RMSEA}=0.074$} \\
\hline \multicolumn{7}{|c|}{ Modification Indices Value (Analysis) } \\
\hline Item & First & Second & Third & Fourth & Fifth & Sixth \\
\hline py $57 \leftarrow$ py 58 & 12.919 & 12.923 & 12.904 & 12.713 & & \\
\hline py $58 \leftarrow$ py 57 & 21.965 & 21.954 & 21.927 & 21.688 & & \\
\hline py $58 \leftarrow$ py 65 & 5.088 & 5.088 & 5.096 & 4.262 & 7.783 & \\
\hline py59<рy64 & 4.257 & 4.250 & 4.251 & 4.405 & 4.517 & 4.535 \\
\hline py62 $<$ py 69 & 4.177 & 4.150 & 4.164 & 4.179 & 4367 & 4.007 \\
\hline py $64 \leftarrow$ py 65 & 6.920 & 6.948 & 6.934 & 8.505 & & 6.534 \\
\hline py $64 \leftarrow$ py 67 & 4.183 & 4.359 & 4.356 & 4.238 & & \\
\hline py $64 \leftarrow$ py 69 & 4.033 & 4.059 & 4.039 & 4.384 & 4.367 & 4.365 \\
\hline py $65 \leftarrow$ ру 66 & 28.998 & 29.013 & 28.999 & & & \\
\hline py $66 \leftarrow$ py 65 & 20.184 & 20.206 & 20.191 & & & \\
\hline py $66 \leftarrow$ py 69 & 6.503 & 6.519 & 6.505 & & & \\
\hline py $66 \leftarrow$ py 70 & 5.404 & 5.415 & 5.432 & & & \\
\hline py $67 \leftarrow$ py 68 & 164.816 & & & & & \\
\hline py $67 \leftarrow$ py 69 & 6.343 & & & & & \\
\hline py68<py67 & 164.903 & & & & & \\
\hline py $69 \leftarrow$ py66 & 4.537 & 4.550 & & & & \\
\hline py69<py67 & 6.334 & 6.337 & & & & \\
\hline py $69<$ py 70 & 140.834 & 140.828 & & & & \\
\hline py70<py69 & 140.762 & 140.758 & & & & \\
\hline \multicolumn{7}{|c|}{ Estimates Value } \\
\hline py57 & & & & & & \\
\hline py58 & & & & & & \\
\hline py59 & & & & & & \\
\hline py60 & & & & & & \\
\hline py61 & & & & & & \\
\hline py62 & & & & & & \\
\hline py63 & & & & & & \\
\hline
\end{tabular}


Figure 4: Communication Elements in CFA

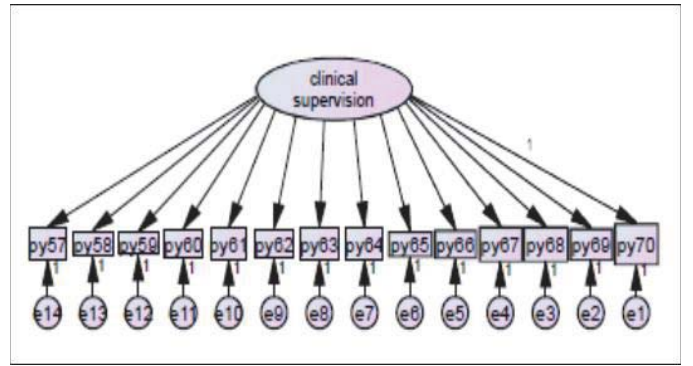

Figure 5: Communication Elements in Model Fit Condition Fulfilled

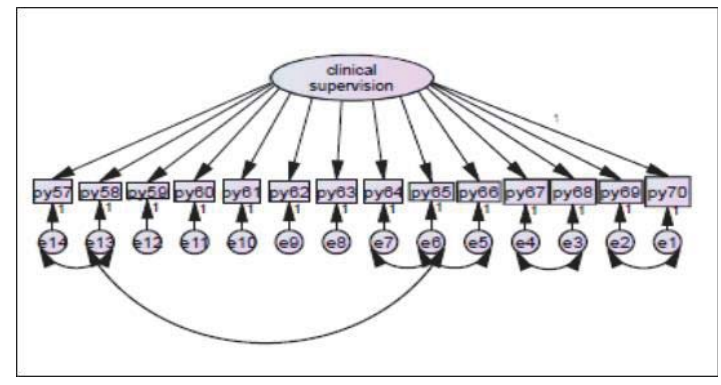

Figure 6: Final Selected of Communication Elements in Model Fit

\subsection{Summary of Findings}

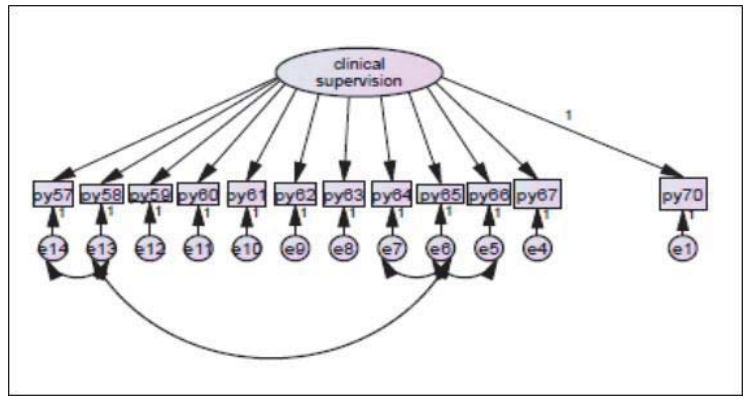

The research has been conducted at two hospitals in Johor Malaysia that is Sultan Ismail, Hospital of Johor Bahru Johor and Sultanah Nora Ismail, Hospital of Batu Pahat Johor. All data collection conducted by survey and questionnaire distribution for collect sample and respondents. The quantity of respondents as research sample is 222.

First objective is reliability and validity testing. The finding has been shown that research the contain validity. Researcher only selects 28 number of questionnaire having related with research field. The research field of study is communication and supervision while in medical training of trainee doctor. The second type of validity test is construct validity. Researcher has been used 28 of questionnaire and only select several questionnaires in the all question have been related with research main purposely. The unrelated questionnaire or too general questionnaire is rejected or unselected. So, the number of each item in communication supervision elements is 7 . Finally, researcher use face validity to confirm all questionnaires as items. Face validity need to confirm by experts in that field of study. Researcher have been selected a number of expert in four research university in Malaysia. All experts selected and critique the items contained is professor and associate professor level. After the face validity has been done, the researcher found that umber of communication and supervision items in elements are changes. The communication increases the number to 10. While, the supervision items in elements have been changes to 14. That is because many clash and repetition or some phases and language usage in original items. Besides the validity testing, researchers also conduct the reliability testing as mention in first objective. The finding has been shown the pilot test showed all items are selected and confirm as items in each elements. All items get very good position in alpha cronbach level.

The second and third of research objective have been related among each other. The findings in objective two affect the objective three finding. Third objective have been shown the analysis Model Fit in communication and supervision elements. Communication elements have been fulfilled the Model Fit condition in one factor analysis. The 
Model Fit has been fulfilled in the fifth analysis in data running. The equation Model Fit are $X^{2} / d f=1.873, R M R=0.080$, $\mathrm{CFI}=\mathbf{0 . 9 7 1}, \mathrm{GFI}=\mathbf{0 . 9 5 3}$, RMSEA=0.063. While, supervision analysis fulfilled condition one factor Model Fit. The model fit has been fulfilled in the seventh analysis in data running. So, second objective in research have been answered.

Objective three in research studies have been answered also from second objective. The research has been concluding that two of items in each element are deleted because having lower than 0.30 of factor loading. Because of that, the items need to be dropped. The item questionnaire in communication elements deleted items number 54 and 56 of. While, in supervision elements have been shown the items question of 68 and 69 has been deleted. So, only 8 items in communication, while 12 items in supervision to develop as an each items.

\section{Conclusion}

The elements are selected as important in trainee doctor learning process. The perfection of supervision and communication affect the trainee doctor learning performance. The communication has been correlated towards supervision, while the supervision needs a good communication to create effective in learning process. Communication make the trainee doctor learning more effective based on discussion, meeting, sharing knowledge among peer and supervision. The supervision makes the trainee doctor more perfectly in learning process. The perfection of learning may occur when the supervisor support and facilitate the supervisee as well as in frequently guidance. So, the impacts of both items help the trainee doctor performance in front of patient perhaps. The conclusion is, trainee doctor need to be clearly communicator towards others especially patients, supervisor, experts learning and other staff in hospital. Also, trainee doctor need follow and observe the rule of supervision in order to achieved the successfully and effective in learning process either in currently situation possibly future performance targets.

\section{References}

Abdul Majeed Alhashen, Habib Alquraini \& Rafiqul I. Chowdhury (2011). Factors Influencing Patient Satisfaction in Primary Healthcare Clinics In Kuwait. The International Journal of Health Care, 24(3), 249-262.

Al Khalid \& Ar Farid (2010). Stopping Doctor-Patient Communication Gap: the Ten Essential Methods. Journal of Community Health, 16(1), 1-6.

Babbie, E. (2002). The Basics of Social Research. (2nd Edition). Wadsworth, Thomson Learning, Chapman University: United States of America.

Brugge, D., Edgar, T., George, K., Heung, J. \& M. Barton, L. (2009). Beyond Literacy and Numeracy in Patient Provider Communication: Focus Groups Suggest Roles for Empowerment, Provider Attitude and Language. Journal of Public Health, 9(3), 354-365.

Bylund, C. L., Brown, R. F., Gueguen, J. A., Diamond, C., Bianculli, J. dan Kissane, D. 2009. The Implementation and Assessment of a Comprehensive Communication Skills Training Curriculum for Oncologists Psycho-Oncology. Journal of Oncology \& Gyncology, 11(10), 110-125.

Bylund, C. L., D' Agostino, T. A., Ho, E. Y., \& Chewning, B. A. (2010). Improving Clinical Communication and Promoting Health Through Concordance-Based Patient Education. Journal of Communication Education, 59 (3), 294-311.

Claudine, C. \& Lindsay, S. C. (2011). Influence of Patients' Self-Respect on their Experience of Feeling Respected in Doctor-Patient Interactions. Journal of Psychology, Health and Medicine, 16(2), 166-177.

Curtis, K., Tzannes, A. \& Rudge, T. (2011). How to Talk to Doctors- A Guide for Effective Communication. Health and Communication of Journal, 58(9), 13-20.

Feng, B., Robert A., Bell, A., Jerant, F. \& Richard L. K. (2011). What do Doctors Say When Prescribing Medications: an Examination of Medical Recommendations from a Communication Perspective. Journal of Health Communication, 26(3), 286-296.

Frieden, T. \& Koplan, J. (2010). Stronger National Public Health Institutes for Global Health. Journal of Medical Education, 376(131), $1721-1722$.

Grant, A. \& Robling M. (2006). Introducing Undergraduate Medical Teaching into General Practice: an Action Research Study. Journal of Medical Teaching, 28(2), 192-197.

Hallahan, K., Derina, H., van ruler, B., Dejan, V. \& Krishnamurthy, S. (2007). Defining Strategic Communication. International Journal of Strategic Communication, 1(1), 3-35.

Hayes, R., Stoudemire, A., Kinlaw, K., Dell, M. \& Loomis, A. (2009). Qualitative Outcome Assessment of a Medical Ethics Programme for Clinical Clerkships: a Pilot Study. Journal General Hospital Psychiatry, 21(10), 284-295.

Hsieh, E. (2006). Understanding Medical Interpreters: Conceptualizing Bilingual Health Communication. Journal of Health Communication, 20(2), 177-186.

Jerant, A., Kravitz, R. L., Azari, R., White, L., Garca, J. A., Vierra, H. \& Franks, P. (2009). Training Residents to Employ Self-EfficacyEnhancing Interviewing Techniques: Randomized Controlled Trial of a Standardized Patient Intervention. Journal of General Internal Medicine, 24(7), 606-613.

Koch-Weser, S., E. Rudd, R. \& Dejong, W. (2010). Quantifying Word Use to Study Health Literacy in Doctor-Patient Communication. 
Journal of Health Communication: International Perspectives, 15(6), 590-602.

Kim, J. \& Kim, S. (2009). Physicians' Perception of the Effects of Internet Health Information on the Doctor-Patient Relationship. Journal of Informatics for Health and Social Care, 34(3), 136-148.

Kumar, P. \& Clark, M. (2005). Clinical Medicine. Edisi Keenam. Spain: Elsevier (Saunders) Limited.

Lane, C. \& Rollnick, S. (2007). The Use of Simulated Patients and Role-Play in Communication Skills. Journal of Health Communication, 12(3), 45-57.

McGill, D. A., van der Vleuten, C. P. \& Clarke, M. J. (2011). Supervisor Assessment of Clinical and Professional Competence of Medical Trainees: A Realibility Study Using Workplace Data and a Focused Analytical Literature Review. Journal of Health Sciences and Education, 16(1), 405-425.

Mcleod, P. J., Steinert, Y., Meagher, T. \& Mcleod, A. (2003). Pedagogy for Clinical Teachers. Journal of Medical Education, 37(11), 638644.

Molapo, M. \& Muula, A. S. (2010). Perspectives of Patients Towards Medical Students at the Queen Elizabeth Central. Journal of Health Research, 12(7), 85-93.

Nobile, C. \& Drotar, D. (2003). Research on the Quality of Parent Provider Communication in Paediatric Care: Implications and Recommendations. Journal of Behavior Pediatric, 24(1), 279-290.

Patel, V. M. (2010). What does Leadership in Surgery Entail. Journal of Surgery, 80(12), 876-883.

Piette, J. D., Heisler, M., Krein, S. \& Kerr, E. A. (2005). The Role of Patientphysician Trust in Moderating Medication Nonadherence Due to Cost Pressures. Archives of Internal Medicine of Journal, 165(73), 1749-1755.

Popoff, D. (2006). The Communication Journal Collection. Journal of Health Communication, 30(3), 71-85.

Puska, P. (2010). From Framingham to North Karelia: from Descriptive Epidemiology to Public Health Action. Progress in Cardiovascular Disease of Journal, 53(1), 15-20.

Ratzan, S. (2010). Moving from IEC to IHC - The Time is Now. Journal of Health Communication, 15(7), 691-694.

Reichelt, S., Gullestad, S. E., Hansen, B. R. Ronnestad, M. H., Torgersen, A. M., Jacobsen, C. H. Nielsen, G. H. \& Skjerve, J. (2009). Nondisclosure in Psychotherapy Group Supervision: the Supervisee Perspective. Nordic Psychology of Journal, 61(4), 5-27.

Reitmanova, S. (2011). Cross-Cultural Undergraduate Medical Education in North America: Theoretical Concepts and Educational Approaches. Journal of Teaching and Learning in Medicine, 23(2), 197-203.

Richard, F. B., Carma, L. B., Jennifer, A. G., Catherine, D., Julia, E. \& David, K. (2010). Developing Patient-Centered Communication Skills Training for Oncologists: Describing the Content and Efficacy Of Training. Journal of Communication Education, 59(3), 235248.

Rider, E. A. \& Keefer, C. H. (2006). Communication Skills Competencies: Definitions and a Teaching Tool Box. Journal of Medical Education, 40(16), 624-629.

Salam, A., Mohd Perdaus, A. F., Md Isa, S. H., Zainuddin, Z., Latiff, A. A., Pheng, N. S., Yusuf, Z., Soelaiman, I. N., Mohamad, N. \& Moktar, N. (2008). UKM Medical Graduates' Perception of their Communication Skills During Housemanship. Journal of Medical and Health, 3(1), 54-58.

Salamonsen, A. (2012). Doctor-Patient Communication and Cancer Patients' Choice of Alternative Therapies as Supplement or Alternative to Conventional Care. Scandinavian Journal of Caring Science, 12(2), 10-11.

Shacak, A. \& Reis, S. (2008). The Impact of Electronic Medical Records on Patient-Doctor Communication During Consultation: a Narrative Literature Review. Journal of Evaluation in Clinical Practice, 15(5), 641-649.

Stead, M. I., Brown, J. M., Fallowfield, L. \& Selby, P. (2003). Lack of Communication Between Healthcare Professionals and Women with Ovarian Cancer About Sexual Issues. British Journal of Cancer, 88(5), 666-671.

Stirrat, G., Johnston, C., Gillon, R. \& Boyd, K. (2010). Medical Ethics and Law for Doctors of Tomorrow: The 1998 Consensus Statement Updated. Journal of Medical Ethics, 36(12), 55-60.

Suter, E. (2009). Role Understanding and Effective Communication as Core Competencies for Collaborative Practice. Journal of Inter Professional Care, 23(10), 41-51.

Tavakol, M., Mohammad, R., Sima, T. \& Jackie, G. (2006). Developments: Opposite Gender Doctor-Patient Interactions in Iran, Teaching and Learning in Medicine. An International Journal, 18(4), 320-325.

Thorne, S. E., Bultz, B. D. \& Baile, W. F. (2005). Is the a Cost to Poor Communication in Cancer Care. A Critical Review of the Literature. Journal of Psycho-Oncology, 14(9), 875-884.

Todres, M., Stephenson, A. \& Jones, R. (2007). Medical Education Research Remains the Poor Relation. British Medical Journal, 335(67), 333-335.

van Ruler, B., Elving, W., Goodman \& M. Genest, C. (2005). Communication Management in the Netherlands: Trends, Development, and Benchmark with US Study. Journal of Communication, 9(3), 32-45.

Veldhuijzen, W., Ram, P. M., Weijden, T., Wassink, M. R. \& van der Vleuten, C. P. (2007). Much Variety and Little Evidence: a Description of Guidelines for Doctor-Patient Communication. Journal of Medical Education, 41(5),138-145.

Williams, J. M. (2002). The Engineering Portfolio: Communication, Reflection, and Student Learning Outcomes Assessment. International Journal of Engineering Education, 18(2), 199-207.

Zaharias, G. Piterman, L. \& Liddell, M. (2013). Doctors and Patients Gender Interaction in the Consultation. Journal of Academic Medicine, 79(1), 48-55. 